\title{
Magnitude of the Mueller-Lyer illusion as a function of lightness contrast, viewing time, and fundus pigmentation
}

\author{
PAMELA C. EBERT and ROBERT H. POLLACK \\ University of Georgia, Athens, Ga. 30601
}

Mueller-Lyer figures of three levels of contrast (1.5 black/, 5 gray/, and 7.5 light gray/, each on 9.5 white/ground) were presented tachistoscopically for $1,500 \mathrm{msec}$ and $500 \mathrm{msec}$ in Mluminant C. Results indicate a significant interaction between contrast level and viewing time. In a second experiment, density of fundus pigmentation was found to be a significant factor in determining illusion magnitude across all contrast levels for a viewing time of $500 \mathrm{msec}$.

The lightness contrast of a figure's inducing lines has been shown by Wickelgren (1965) to influence the magnitude of illusion as a function of the amount of contrast. Pollack \& Silvar (1967), using achromatic Mueller-Lyer figures, demonstrated that gross differences in fundus pigmentation were also related to the magnitude of illusion in preadolescent boys, with darkly pigmented Ss being significantly less sensitive (susceptible) to illusory factors than lightly pigmented Ss. At the same time, Pollack (1966) suggested that an increased density of retinal pigmentation with age may be responsible for diminishing the sensitivity of the visual receptor system to figure-ground contrast. Many workers (Binet, 1895; van Biervliet, 1896; Piaget \& von Albertini, 1952; Wapner \& Werner, 1957; Pollack, 1963, 1964, $1970 \mathrm{~b})$ have presented evidence showing a decrease in magnitude of illusion as a function of age using figures produced by lightness contrast.

In a preliminary investigation reported by Ebert \& Pollack (1971) viewing time was shown to be yet another factor influencing the magnitude of the Mueller-Lyer illusion.

This investigation was undertaken to determine the effects of lightness contrast, viewing time, and amount of fundus pigmentation on the magnitude of the Mueller-Lyer illusion. The results of the first experiment necessitated further research to clarify the influence of fundus pigmentation.

$$
\text { EXPERIMENT } 1
$$$$
\text { Subjects }
$$

The Ss were 20 male and 20 female white undergraduate students ranging in age from 18 to 25 years, all having uncorrected visual acuities of $20 / 20$ or better.

\section{Apparatus}

Each stimulus consisted of the open component (forked ends connected by a straight line) of the Mueller-Lyer figure and a straight unbounded comparison line. All lines were $1 \mathrm{~mm}$ thick. The oblique inducing lines were $5 \mathrm{~mm}$ long, and the standard between the obliques was $22 \mathrm{~mm}$ in length. The comparison lines varied in $0.5-\mathrm{mm}$ steps from 20 through $29 \mathrm{~mm}$. Each comparison line was mounted on a 35-mm square field consisting of Munsell white paper. The standard illusion figure was also mounted on each slide. Both figures were vertical and placed symmetrically, one $5 \mathrm{~mm}$ to the left and one $5 \mathrm{~mm}$ to the right of a central fixation point. The maximal visual angle was $1 \mathrm{deg} 7 \mathrm{~min}$ in the vertical dimension.

The figures were constructed of Munsell papers, yielding three levels of lightness contrast: $1.5 / \mathrm{black}$, 5/gray, and $7.5 /$ light gray, each on $9.5 /$ white ground.

Measures of fundus pigmentation were obtained for each $\mathrm{S}$, using a highly sensitive Photovolt light meter connected to one eyepiece of a Bausch and Lomb binocular ophthalmoscope. A scale of reflectance was derived from the photometric scale. The range of reflectance varied from 2 (dark) to 20 (light), with each unit representing a light (photometric) value of $5 \mathrm{x}$ $10^{-7} \mathrm{fc}$ or $0.001 \mathrm{microlumen}$. Readings of fundus reflectance were taken for each $S$ from a point on the retina just to the left of the foveal depression.

\section{Procedure}

The Ss were divided into two equal groups, each comprising 10 males and 10 females. The figures were presented tachistoscopically at a viewing distance of $1,500 \mathrm{~mm}$ in Illuminant $\mathrm{C}$. The first group viewed the figures for $1,500 \mathrm{msec}$, while the second group viewed the figures for $500 \mathrm{msec}$. The order of presentation of contrast levels was randomized across Ss, all Ss receiving the three levels of lightness contrast. Left or right location of the standard was counterbalanced throughout trials.

A converging method of limits was used, with six trials for each contrast level.

Results

PSEs were obtained for each trial, and the mean PSE across trials was calculated for each S. Since earlier results (Pollack, 1970a) indicated no sex differences in illusion scores, this dimension was ignored. The data were analyzed by viewing time and across contrast levels using a mixed model ANOVA for repeated measures across contrast levels and independence for viewing time (McNemar, 1969). No significant main effect for time was found, while the contrast effect approached significance $(F=2.37$, $\mathrm{df}=2,76, \quad \mathrm{p}<.10) . \quad$ A significant interaction occurred between contrast level and viewing time $(F=20.14$, df $=2,76, p<.001$ ).

One-way ANOVAs were calculated for each level of viewing time. A significant difference in illusion magnitude for each contrast level was indicated for each viewing time $(1,500 \mathrm{msec}-\mathrm{F}=9.7035$, df $=2,38$, $\mathrm{p}<.001 ; 500 \mathrm{msec}-\mathrm{F}=54.095$, $\mathrm{df}=2,38, \quad \mathrm{p}<.001)$. Appropriate Newman-Keuls tests for paired comparisons indicated that the light gray contrast level differed significantly from the black and from the midgray $(p<.01)$ at a viewing time of $1,500 \mathrm{msec}$, while all levels of contrast at a viewing time of $500 \mathrm{msec}$ differed, with light gray producing a smaller illusion than midgray, which produced a smaller illusion than black $(p<.01$.

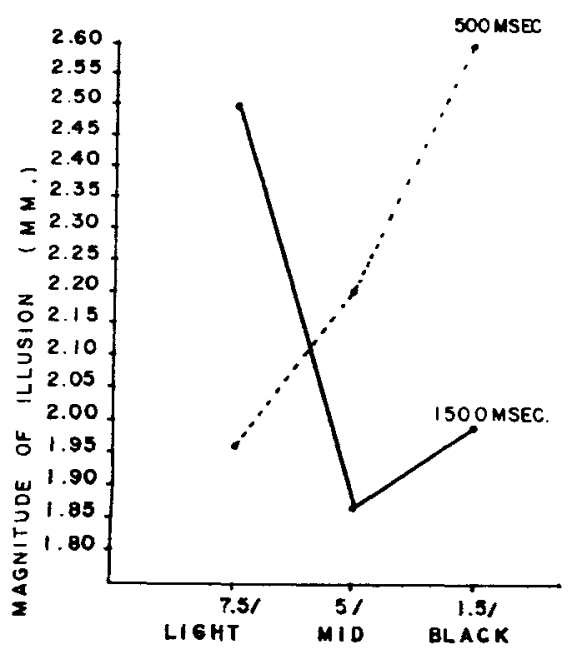

CONTRAST LEVEL

Fig. 1. Ilusion magnitude as a function of contrast level and viewing time. 


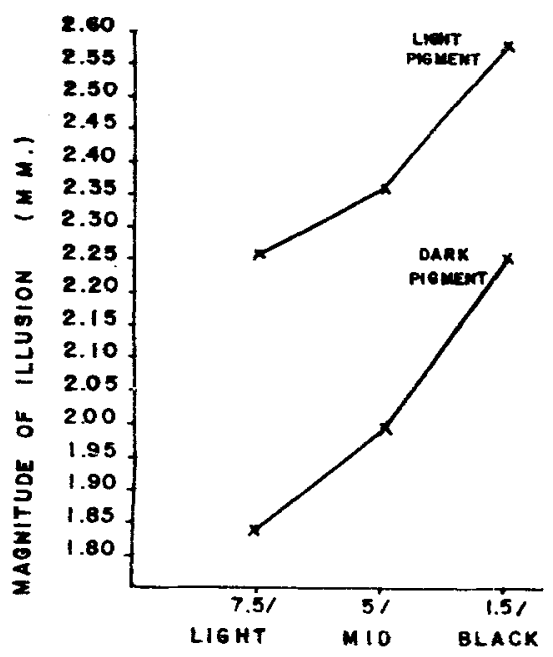

C ONTRAST LEVEL

Fig. 2. Mlusion magnitude as a function of fundus pigmentation and contrast level for a viewing time of $\mathbf{5 0 0}$ msec.

Product-moment correlations between fundus pigmentation and lightness contrast for each viewing condition were negligible. However, the suggestion of a trend for the 500-msec condition seemed to call for further study.

\section{EXPERIMENT 2 \\ Subjects}

The Ss were 25 male and 25 female white undergraduate students, ranging in age from 18 to 25 years and all having uncorrected visual acuities of $20 / 20$ or better. Data from the original 10 male and 10 female Ss were employed, the sample expanded by adding 15 Ss of each sex.

Procedure

The stimuli described in the first experiment were again used here, with three levels of lightness contrast presented to each $S$ at an exposure time of $500 \mathrm{msec}$. The order of presentation was randomized across
Ss, and a converging method of limits was used. Measures of fundus pigmentation were taken for each $S$.

\section{Results}

Owing to a bimodal distribution of pigmentation readings, the sample was divided for analysis so that $25 \mathrm{Ss}$ occupied the "darkly pigmented" category, while 25 Ss were classified as "lightly pigmented." A 2 by 3 mixed model ANOVA for repeated measures was calculated. The results indicate a significant main effect of pigmentation $(F=5.617, \mathrm{~d} f=2,94, p<.05)$, as well as a significant effect of contrast level $(\mathrm{F}=10.794, \mathrm{df}=2,94, \mathrm{p}<.001)$. The interaction effect was not significant. DISCUSSION

The results of the first experiment clearly indicate that the magnitude of the Mueller-Lyer illusion is influenced not only by the level of lightness contrast, but that the direction of illusion magnitude across contrast levels can be ordered as a function of viewing time. The significant linear increase in illusion magnitude from light gray to black at a viewing time of 500 msec would seem to suggest that the integrating mechanism operating at this viewing time differs from that process occurring during more prolonged presentation, as the results for the 1,500-msec condition indicate.

Pollack (1970b) has argued that fundus pigmentation may be an important factor in processing figure-ground contrast. The results of the second experiment indeed indicate that the density of fundus pigmentation is a critical factor in determining the magnitude of the Mueller-Lyer illusion across all levels of contrast in the condition of reduced viewing time.

Overall, the findings suggest that viewing time is a significant variable because of its interaction with lightness contrast level. Furthermore, fundus pigmentation is a significant factor influencing the magnitude of illusion across all levels of contrast during shorter tachistoscopic presentations, the exact nature of which is being explored at the present time.

\section{REFERENCES}

BINET, A. La mesure des illusions visuelles chez les enfants. Revue Philosophique, $1895,40,11-25$

EBERT, P.. \& POLLACK, R. H. Magnitude of the Mueller-Lyer illusion as a function of hue, saturation and fundus pigmentation. Paper presented at the meeting of the Eastern Psychological Association, New York, April 1971.

MeNemar, Q. Psychological Statistics, (4th ed.) New York: Wiley, 1969

PI A GET, J., \& von ALBERTINI, B. L'illusion de Mueller-Lyer. Archives de Psy chologie, 1950, 33, 1-48.

POLLACK, R. H. Contour detectability thresholds as a function of chronological age. Perceptual \& Motor Skills, 1963, 17. $411-417$.

POLLACK, R. H. Simultaneous and successive presentation of elements of the Mueller-Lyer figure and chronological age. Perceptual \& Motor Skills, 1964, 19 303-310.

POLLACK, R. H. Non-developmental age changes in the perception of children. In N. S. Jenkins and R. H. Pollack (Eds.), Perceptual development: Its relation to theories of intelligence and cognition. Proceedings of a conference sponsored by the Institute for Juvenile Research and National Institute of Child Health and Human Development, Chicago, 1966. Pp. 82-102

POLLACK, R. H. Magnitude of the Mueller-Lyer illusion as a function of hue in the absence of lightness contrast. Proceedings of the American Psychological Association, 1970a, 53-54.

POLLACK, R. H Mueller-Lyer illusion: Effect of age, lightness contrast, and hue. Science, $1970 \mathrm{~b}, 170,93-95$.

POLLACK, R. H., \& SILVAR, S. Magnitude of the Mueller-Lyer illusion in children as a function of pigmentation of the fundus oculi. Psychonomic Science, 1967,8, 83-84.

van BIERVLIET, J. J. Nouvelles mesures des illusions visuelles chez les adultes et les enfants, Revue Philosophique, 1896 , 41, 169-181.

WAPNER, S., \& WERNER, H, Perceptual development. Worcester, Mass: Clark University Press, 1957.

WICKEL GREN, G. G. Brightness contrast and length perception in the Mueller-Lyer illusion. Vision Research, 1965,5 , 141-150. 